\title{
Optical properties of ZnMgO films grown by spray pyrolysis and their application to UV photodetection
}

\author{
M Lopez-Ponce , A Hierro , V Marín-Borrás , G Tabares , A Kurtz , \\ S Albert , S Agouram , V Muñoz-Sanjosé , E Muñoz ${ }^{1}$ and J M Ulloa
}

\begin{abstract}
This work presents a comprehensive optical characterization of $\mathrm{Zn}_{1-x} \mathrm{Mg}_{x} \mathrm{O}$ thin films grown by spray pyrolysis (SP). Absorption measurements show the high potential of this technique to tune the bandgap from 3.30 to $4.11 \mathrm{eV}$ by changing the $\mathrm{Mg}$ acetate content in the precursor solution, leading to a change of the $\mathrm{Mg}$-content ranging from 0 up to $35 \%$, as measured by transmission electron microscopy-energy dispersive x-ray spectroscopy. The optical emission of the films obtained by cathodoluminescence and photoluminescence spectroscopy shows a blue shift of the peak position from 3.26 to $3.89 \mathrm{eV}$ with increasing $\mathrm{Mg}$ incorporation, with a clear excitonic contribution even at high $\mathrm{Mg}$ contents. The linewidth broadening of the absorption and emission spectra as well as the magnitude of the observed Stokes shift are found to significantly increase with the Mg content. This is shown to be related to both potential fluctuations induced by pure statistical alloy disorder and the presence of a tail of band states, the latter dominating for medium $\mathrm{Mg}$ contents. Finally, metal-semiconductor-metal photodiodes were fabricated showing a high sensitivity and a blue shift in the cut-off energy from 3.32 to $4.02 \mathrm{eV}$, i.e., down to $308 \mathrm{~nm}$. The photodiodes present large $\mathrm{UV} /$ dark contrast ratios $\left(10^{2}-10^{7}\right)$, indicating the viability of SP as a growth technique to fabricate low cost $(\mathrm{Zn}, \mathrm{Mg}) \mathrm{O}$-based UV photodetectors reaching short wavelengths.
\end{abstract}

Keywords: $\mathrm{ZnO}$, photodetectors, $\mathrm{ZnMgO}$, spray pyrolysis, optical characterization, Stokes shift, MSM

\section{Introduction}

Extending the photodetection wavelength from the near to the middle ultraviolet (UV) is an area of major interest for numerous applications, including solar blind photodetection, among others [1-4]. The ternary $(\mathrm{Zn}, \mathrm{Mg}) \mathrm{O}$ is one of the most promising semiconductor candidates for the short-wavelength region of the electromagnetic spectrum. Indeed, several publications have already demonstrated the capabilities of wurtzite $(\mathrm{Zn}, \mathrm{Mg}) \mathrm{O}$ based-photodetectors using Schottky diodes [5], metal-semiconductor-metal (MSM) [6] or metalinsulator-semiconductor (MIS) [7] photodiodes, covering the spectral region between 270 and $370 \mathrm{~nm}$. In theory, by alloying $\mathrm{ZnO}$ with $\mathrm{MgO}$ it is possible to tune the bandgap from 3.37 to $7.80 \mathrm{eV}$ [8]. However, as a consequence of their different crystal structures, the maximum $\mathrm{Mg}$ content incorporated into the $\mathrm{ZnO}$ lattice keeping the wurtzite structure has been found to be $56 \%$ ( $\left.E_{\mathrm{G}} \sim 4.56 \mathrm{eV}\right)$ using molecular beam epitaxy (MBE) [1, 9]. High $\mathrm{Mg}$ contents yield to phase separation, and the cubic phase starts to dominate $[10,11]$. Depending on the growth technique the $\mathrm{Mg}$ solubility can vary widely. Using MBE, pulsed laser deposition or metal organic chemical vapor deposition (MOCVD) it is possible to reach high $\mathrm{Mg}$ contents up to $\sim 50 \%[1,9,10,12]$. In 
contrast, the $\mathrm{Mg}$ solubility decreases with other growth techniques such as magnetron sputtering $(\sim 46 \%)$ [13], solgel $(\sim 30 \%)$ [14] or spray pyrolysis (SP) $(\sim 30 \%)[15,16]$. Several reports have shown $(\mathrm{Zn}, \mathrm{Mg}) \mathrm{O}$-based photodetectors with high sensitivity in the UV range even using cost-effective growth approaches [17, 18]. Among these techniques SP is generating a great deal of interest due to its potential in low cost applications as a result of its process simplicity and scalability [15, 19-21]. Despite the advantages offered by this technique, there are only a few reports demonstrating ( $\mathrm{Zn}$, $\mathrm{Mg}$ )O-based photodetectors with inferior results compared to other techniques [15]. Improvements in the crystal quality of the films and in the increase of the solubility limit of $\mathrm{Mg}$ have to be achieved in order to be able to demonstrate high performance photodetectors in the mid-UV.

In this letter we report on the optical characterization of high crystallinity $\mathrm{Zn}_{1-x} \mathrm{Mg}_{x} \mathrm{O}$ films grown by $\mathrm{SP}$ with $\mathrm{Mg}$ concentrations as high as $35 \%$ and bandgap energies up to $\sim 4.11 \mathrm{eV}$. A detailed analysis of the absorption and emission properties of the films is used to identify and understand the optical characteristics resulting from the high $\mathrm{Mg}$ contents. MSM photodiodes based on the ( $\mathrm{Zn}, \mathrm{Mg}) \mathrm{O}$ films have been fabricated and show absorption edges extending well into the UV with high responsivity values and large UV/dark contrast ratios. Thus, we demonstrate with this study the great potential of SP to grow high quality structures operating in the UV spectral region.

$\mathrm{Zn}_{1-x} \mathrm{Mg}_{x} \mathrm{O}$ films were grown on c-plane sapphire substrate by SP. Zinc acetate dihydrate $\left(\mathrm{Zn}\left(\mathrm{CH}_{3} \mathrm{COO}\right)_{2} \cdot 2 \mathrm{H}_{2} \mathrm{O}\right)$ and magnesium acetate tetrahydrate $\left(\mathrm{Mg}\left(\mathrm{CH}_{3} \mathrm{COO}\right)_{2} \cdot 4 \mathrm{H}_{2} \mathrm{O}\right)$ solutions dissolved in methanol were chosen as the sources for $\mathrm{Zn}$ and $\mathrm{Mg}$, respectively. The growth time was maintained constant for all the samples $(60 \mathrm{~min})$, yielding film thicknesses from 200 to $500 \mathrm{~nm}$ as a result of the dependence of the growth rate on the $\mathrm{Mg}$ content. Adjusting the $\mathrm{Mg}$ molar concentration in the precursor solution, the $\mathrm{Mg}$ content was varied between 0 and $35 \%$ (measured by TEM-EDX). The substrate growth temperature was $525^{\circ} \mathrm{C}$. The precursor was sprayed using $\mathrm{N}_{2}$ as a carrier gas. The ( $\mathrm{Zn}, \mathrm{Mg}$ )O samples were optically characterized by UV-VIS spectrophotometry, and low temperature photoluminescence (PL) and room temperature (RT) cathodoluminescence (CL) spectroscopies. The absorption spectra were recorded at RT with a Jasco V-650 spectrophotometer, whereas the CL measurements were performed using a Gatan MonoCL4 spectrometer connected to a FEI Inspect F50 scanning electron microscope. Low temperature PL measurements were done in backscattering configuration by using a $\mathrm{He}-\mathrm{Cd}$ laser $(\lambda=325 \mathrm{~nm})$ and a monochromator-based system. TEMEDX was performed using a field emission FEI TECNAI G2 F20 transmission electron microscope to obtain the real $\mathrm{Mg}$ content present on the films. Finally, MSM photodiodes were fabricated and characterized. The spectral response of the MSM photodiodes was measured using a $1000 \mathrm{~W}$ Xe-lamp with a $1 / 4 \mathrm{~m}$ monochromator under steady state conditions with an optical power density of $\sim 10^{-2} \mathrm{~W} \mathrm{~cm}^{-2}$. The absolute illumination power was estimated with a calibrated UVenhanced $\mathrm{Si}$ photodiode and a pyrometer.
Figure 1(a) shows the RT absorption spectra of the $\mathrm{Zn}_{1-x} \mathrm{Mg}_{x} \mathrm{O}$ films. It can be seen that all films present a sharp absorption edge which is clearly shifted towards higher energies with increasing $\mathrm{Mg}$ concentration. The bandgap energy was extracted for all compositions assuming the model proposed by Srinivasan et al in which the bandgap energies correspond to the energy at which the slope of the absorption spectrum is maximized [22]. This approach accounts well for the presence of an Urbach tail and for the transition to the band-to-band absorption. Figure 1(b) shows the relationship between the extracted bandgap and the $\mathrm{Mg}$ concentration measured by TEM-EDX in the same films. As it can be seen, the bandgap increases linearly from 3.30 to $4.11 \mathrm{eV}$ for $\mathrm{Mg}$ increasing up to $\sim 35 \%$. This result demonstrates that $\mathrm{Mg}$ is well incorporated into the $\mathrm{ZnO}$ wurtzite structure. In the literature, there are several publications demonstrating $(\mathrm{Zn}, \mathrm{Mg})$ O films with energy bandgaps close to $4 \mathrm{eV}$ using the same growth technique [15, 23]. Nevertheless, the results reported here show the largest bandgap energy reported for $(\mathrm{Zn}, \mathrm{Mg}) \mathrm{O}$ films grown by SP [15, 23].

It is interesting to note that the extracted bandgap energies follow well a linear dependence on $\mathrm{Mg}$ content, indicating the low bandgap bowing present in this ternary alloy due to the similar atomic size of $\mathrm{Mg}$ and $\mathrm{Zn}$ [24]. Fitting a linear expression to the measured bandgap, the dependency $E_{\text {Bandgap }}(x)=2.28 \cdot x+3.30 \mathrm{eV}$ is obtained, which matches very well those previously published by other groups $[11,25]$. Increasing $\mathrm{Mg}$ content does however have an impact on the width and shape of the absorption edge (figure 1(a)). In order to quantify this effect, we have adopted the sigmoidal fit, $\alpha=\alpha_{0} /\left(1+\exp \left(\left(E_{\text {Bandgap }}-E\right) / \Delta E\right)\right)$, to calculate the absorption edge width $(\Delta E)$, which describes the abruptness of the absorption edge. Figure 1(c) shows that indeed $\Delta E$ increases with $\mathrm{Mg}$ content, suggesting a degradation of the crystal quality. Furthermore, for the largest $\mathrm{Mg}$ contents ( $x=0.3$ and 0.35 ) two absorption edges are clearly observed. This phenomenon could be related to both the appearance of stable $(\mathrm{Zn}, \mathrm{Mg}) \mathrm{O}$ wurtzite clusters and the beginning of phase separation. In order to clarify the origin of these absorption bands and the increase of $\Delta E, C L$ and PL have been performed on these samples.

As shown in figure 2(a), the RT CL spectra show a well defined near-band edge transition (NBE) that is blue shifted from 3.27 to $3.89 \mathrm{eV}$ with increasing $\mathrm{Mg}$ content (figure 2(b)), following a linear behavior. Besides, the wellknown broad green band luminescence which is associated with $\mathrm{Zn}$ and $\mathrm{O}$ vacancies, is observed in all the CL spectra [26]. Fitting the experimental NBE energy values, the expression $E_{\mathrm{CL}}(x)=1.67 \cdot x+3.27 \mathrm{eV}$ is obtained. In this case, the slope is lower than that obtained in the absorption measurements, indicating the presence of a Stokes energy shift, which increases with $\mathrm{Mg}$ content. Besides that, the full width at half maximum (FWHM) of the dominant CL peak also increases with $\mathrm{Mg}$ content from $244 \mathrm{meV}$ for $\mathrm{ZnO}$, up to $347 \mathrm{meV}$ for the $35 \% \mathrm{Mg}$ film (figure 2(c)). However, the sample with $30 \%$ of $\mathrm{Mg}$ presents the largest FWHM, $470 \mathrm{meV}$. This increase in FWHM arises from the presence of two emission bands, which are merging in the sample with 


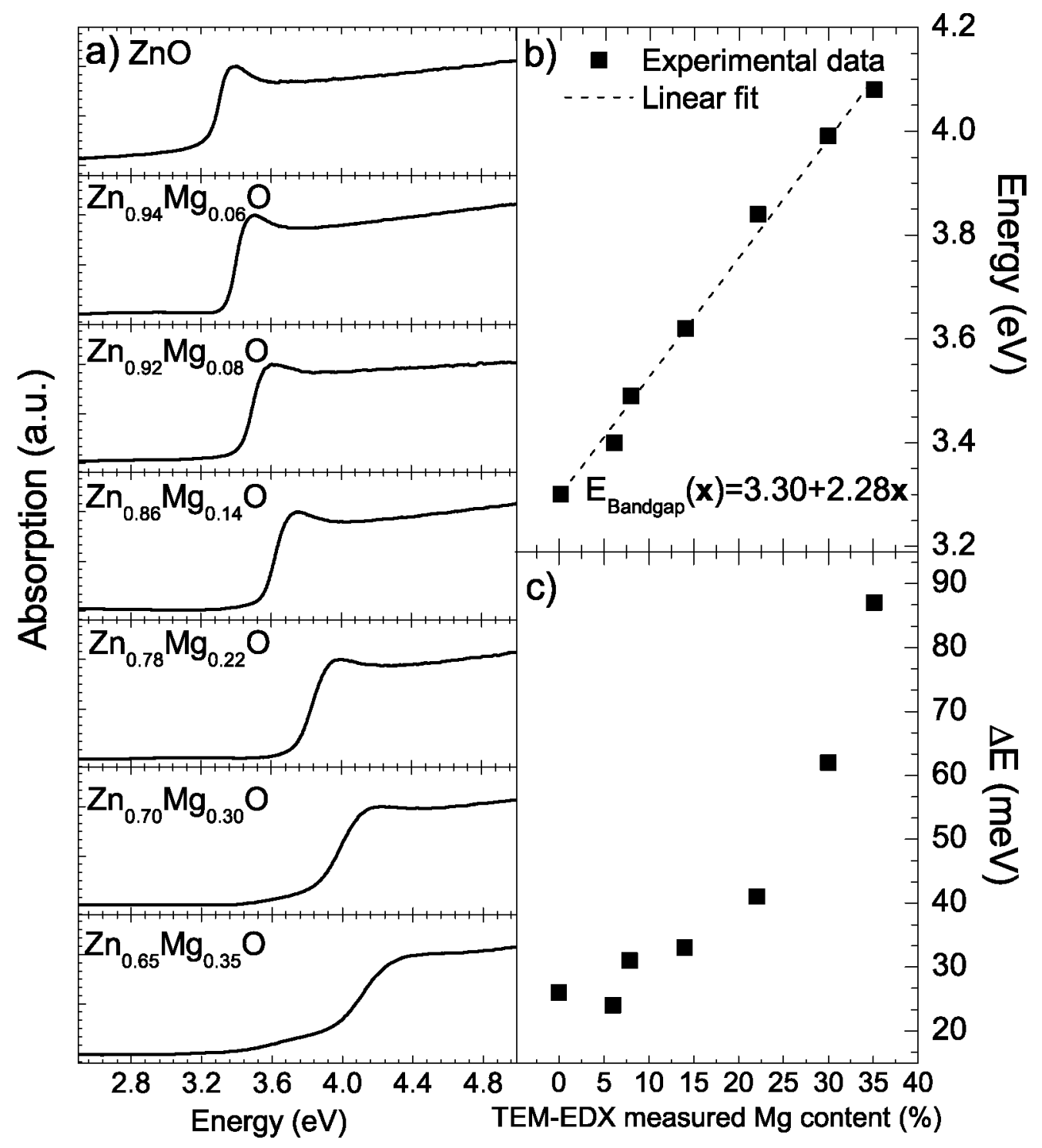

Figure 1. (a) Room temperature absorption spectra of the ( $\mathrm{Zn}, \mathrm{Mg}) \mathrm{O}$ films with different $\mathrm{Mg}$ contents. (b) Absorption edge energy and (c) $\Delta E$, which is related with the absorption edge width, are represented as a function of $\mathrm{Mg}$ content.

$30 \% \mathrm{Mg}$ content and are well separated in the sample with $35 \% \mathrm{Mg}$ content. This new lower energy band matches well the previously discussed absorption results, and appears to be related to the onset of phase separation.

The broadening of both the optical absorption and emission with increasing $\mathrm{Mg}$ is likely related to a degradation of the crystal quality, which includes lattice distortion, generation of defects, or local alloy fluctuations. In addition, statistical alloy disorder could also affect the observed broadening. The combination of all of these effects can be quantified through the Stokes shift, which is defined as the energy difference between the optical emission peak and the absorption edge. As it is shown in figure 3, the Stokes shift was found to increase considerable from $\sim 30$ to $\sim 230 \mathrm{meV}$ with increasing $\mathrm{Mg}$. This strong dependence matches very well the observed increase of the FWHM and $\Delta E$ discussed earlier. For comparison, the Stokes shift values obtained by other groups using epitaxial growth techniques, such as MOCVD [25] or MBE [27], matches very well with our measured values for all $\mathrm{Mg}$ contents. In the case of MOCVD a maximum value around $\sim 270 \mathrm{meV}$ have been obtained for a $\mathrm{Mg}$ content of $20 \%$. However, lower values have been reached using MBE ( $\sim 120 \mathrm{meV}$ with $27 \%$ of $\mathrm{Mg}$ ). Typically, local compositional fluctuations are present in ternary alloys and cause a broadening of the emission line width. In the case of $(\mathrm{Zn}, \mathrm{Mg}) \mathrm{O}$, local $\mathrm{Mg}$ inhomogeneities yield potential fluctuations in the bandgap leading to strong exciton localization. That degree of localization increases with $\mathrm{Mg}$ content, as it can be deduced from the increase of the Stokes shift with increasing Mg. Similar results have been reported by other groups showing that the energy fluctuations in $\mathrm{Mg}$ rich samples are higher than that in $\mathrm{Mg}$ poor ones [25, 27, 28]. Moreover, $\mathrm{ZnO}$ and $\mathrm{MgO}$ have a very small exciton Bohr radius $\left(r_{\mathrm{B}}\right)$ compared with other III-V and II-VI semiconductors. Therefore, excitons are localized over a small volume which implies that they are strongly influenced by $\mathrm{Mg}$ inhomogeneities. Moreover, since the Bohr radius is $\sim 1.8 \mathrm{~nm}$ in $\mathrm{ZnO}$ and $\sim 0.8 \mathrm{~nm}$ in $\mathrm{MgO}$ [29], it is reasonable to assume 


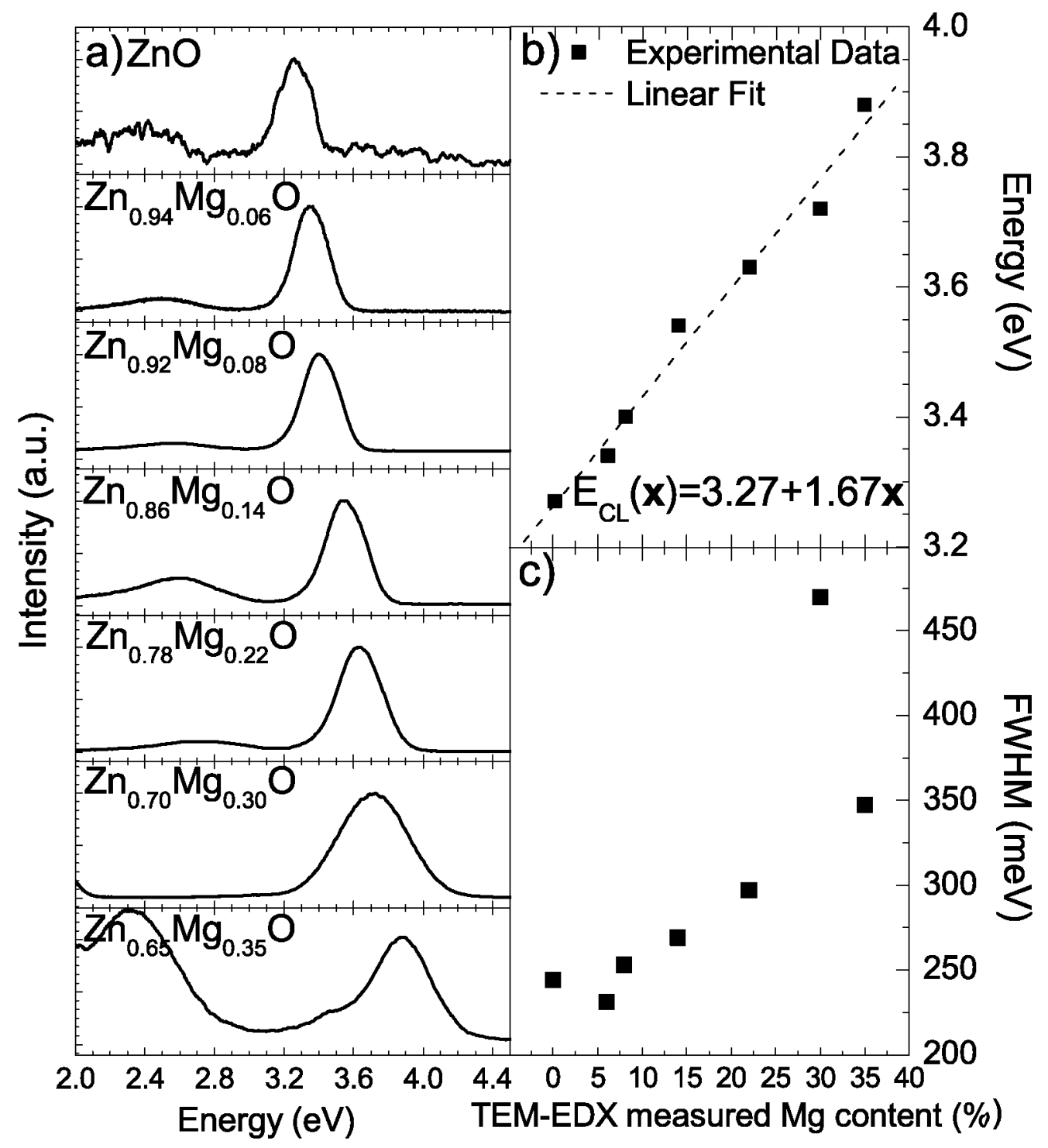

Figure 2. (a) Room temperature CL spectra of the ( $\mathrm{Zn}, \mathrm{Mg}) \mathrm{O}$ films with different $\mathrm{Mg}$ contents. (b) CL peak energy and (c) CL FWHM are represented as a function of $\mathrm{Mg}$ content.

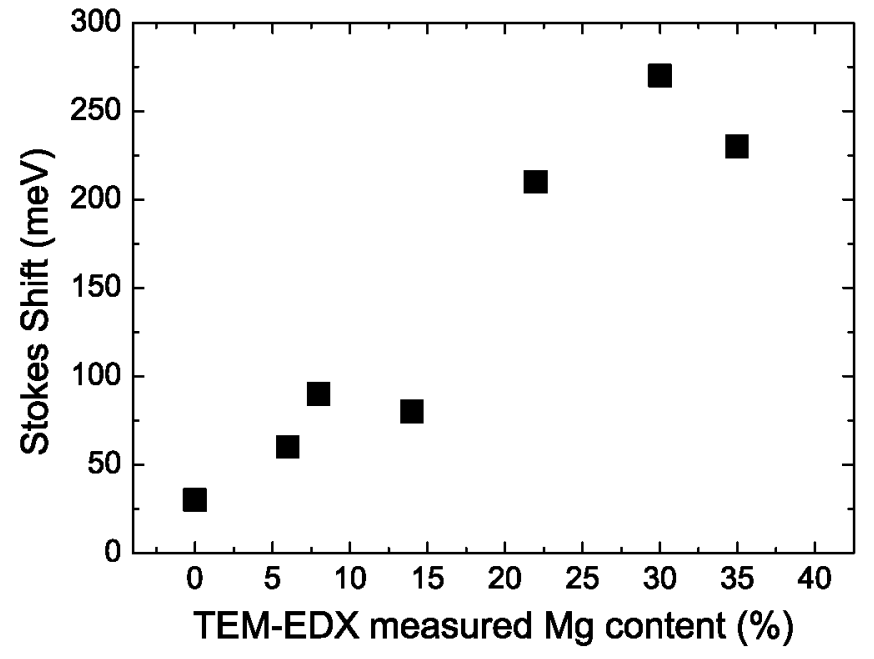

Figure 3. Stokes shift of the $(\mathrm{Zn}, \mathrm{Mg}) \mathrm{O}$ films as a function of the $\mathrm{Mg}$ content. that in the $(\mathrm{Zn}, \mathrm{Mg}) \mathrm{O}$ ternary alloy it decreases with $\mathrm{Mg}$ content being more sensitive to localization in potential minima, thus producing a broadening of the optical line width $[10,25]$.

As it was mentioned above, part of the increase in the line width is likely arising from statistical alloy disorder in the ( $\mathrm{Zn}, \mathrm{Mg}$ )O ternary alloy. In order to quantify this effect, low temperature $(8 \mathrm{~K}) \mathrm{PL}$ measurements were performed (figure 4(a)). Due to the excitation source energy used for the PL measurements ( $\mathrm{He}-\mathrm{Cd}$ laser at $325 \mathrm{~nm}$ ) only samples with $\mathrm{Mg}$ content lower than $14 \%$ could be measured. The PL peak is found to be blue shifted from 3.36 to $3.59 \mathrm{eV}$ for $\mathrm{Mg}$ contents ranging from 0 to $14 \%$, as seen before in CL. In the pure $\mathrm{ZnO}$ spectra different peaks can clearly be distinguished. The most intense peak is related to the donor-bound exciton transition $\left(\mathrm{D}^{0} \mathrm{X}\right)$ which is centered at $3.3604 \mathrm{eV}$, whose phonon replicas are also observed [26]. The transition at $3.327 \mathrm{eV}$ together with very well defined phonon replica (LO) may be related to recombination at stacking faults 

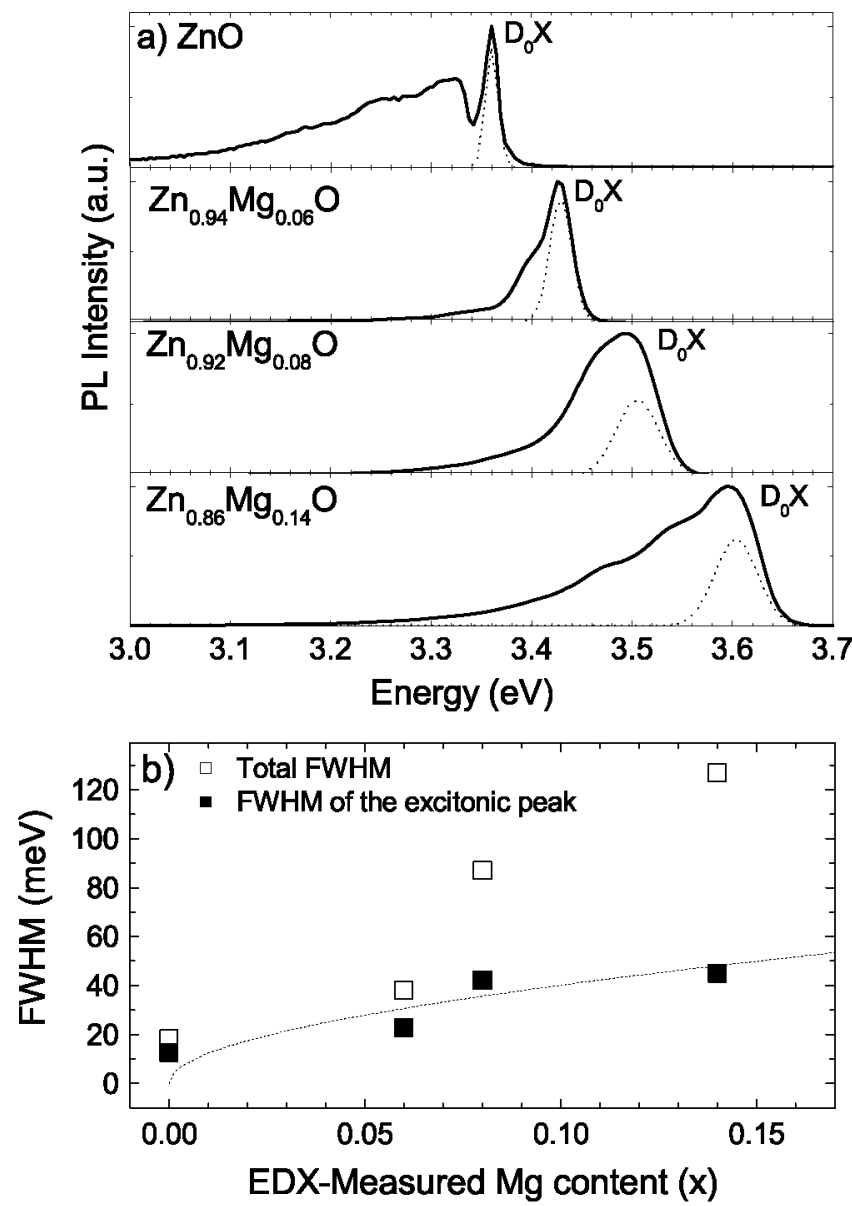

Figure 4. (a) Low temperature ( $8 \mathrm{~K}) \mathrm{PL}$ spectra of the $(\mathrm{Zn}, \mathrm{Mg}) \mathrm{O}$ layers. The dotted line represents the extracted $\mathrm{D}^{0} \mathrm{X}$ emission. (b) FWHM of the total emission and of the $\mathrm{D}^{0} \mathrm{X}$ excitonic transition as a function of $\mathrm{Mg}$ content. The dotted line is the approximation of the FWHM according to the statistical alloy disorder model discussed in the text.

(figure 4(a)) [30]. These transitions are still present when $\mathrm{Mg}$ is incorporated but are less defined due to the linewidth broadening effect. In agreement with the CL measurements, the PL linewidth increases with $\mathrm{Mg}$ content. This is shown in figure 4(b), where we have differentiated the total broadening of the PL emission and the broadening contribution due to the dominant excitonic emission $\left(\mathrm{D}^{0} \mathrm{X}\right)$, which has been obtained using a Gaussian fit. In the case of the $\mathrm{ZnO}$ film, the difference between the total broadening $(\sim 18 \mathrm{meV})$ and the one related to the excitonic emission $(\sim 13 \mathrm{meV})$ is small. However, this difference becomes larger with increasing $\mathrm{Mg}$ content, reaching a maximum for the highest $\mathrm{Mg}$ concentration (figure 4(b)).

Using the model introduced by Schubert et al [31] and Zimmermann [32] we can quantify the contribution of statistical alloy disorder to the PL FWHM of the excitonic peak. This approximation considers the variation of the exciton transition energy with alloy content, the volume of the elementary cell, and the volume of the exciton. In addition, the lattice parameters $c$ and $a$, characteristic of the wurtzite structure, and the Bohr radius, have been estimated assuming a linear dependency with $\mathrm{Mg}$ content from $\mathrm{ZnO}$ to wurtzite
$\operatorname{MgO}[25,27,33]$. The dotted line in figure 4(b) represents the calculated broadening as a function of $\mathrm{Mg}$ content according to the model. As we can observe, the calculated line is in good agreement with the results obtained for the excitonic lines, but clearly only accounts for a small portion of the total linewidth increase. Thus, we can conclude that the large increase in Stokes shift and the observed broadening with increasing $\mathrm{Mg}$ is only partially limited by statistical alloy disorder. For middle $\mathrm{Mg}$ contents the contribution from a tail of states below the bandgap dominates, whereas at large $\mathrm{Mg}$ contents $(>30 \%)$ the presence of different absorption and emission bands indicates the onset of phase separation.

Using these films, MSM-photodiodes with an interdigitated electrode geometry (32 pairs) were processed and an optical sensitive area of $10^{-4} \mathrm{~cm}^{2}$. The electrodes are $5 \mu \mathrm{m}$ wide and separated $1 \mu \mathrm{m}$. The top contact consisted of a $80 \mathrm{~nm}$ thick Au film evaporated onto the ( $\mathrm{Zn}, \mathrm{Mg}) \mathrm{O}$ surface. Figure 5(a) shows the spectral response for $\mathrm{Zn}_{1-x} \mathrm{Mg} \mathrm{g}_{x} \mathrm{O}$ MSM-photodiodes at $1 \mathrm{~V}$ for three representative $\mathrm{Mg}$ contents: $x=0,0.14$, and $x=0.35$. Extracting the photocurrent cut-off energy from the MSM photodiodes, a shift from 3.32 to $4.02 \mathrm{eV}$ is observed (figure 5(a)). The cut-off energy shifts to the higher energy side with increasing $\mathrm{Mg}$ concentration, again showing a linear dependence from the $\mathrm{Mg}$ content which is similar to that obtained in absorption measurements $\left(E_{\text {Cut-off }}(x)=1.92 \cdot x+3.32 \mathrm{eV}\right.$ ) (figure 6(a)). Above the photodiode cut-off energy, all of the samples exhibit a very high responsivity. However, a significant decrease in responsivity with increasing $\mathrm{Mg}$ content is found: from $3 \times 10^{3}$ to $4 \times 10^{2} \mathrm{~A} / \mathrm{W}$ from 0 to $35 \% \mathrm{Mg}$, effect that could be related to the reduction of the intrinsic carrier concentration with $\mathrm{Mg}$ [34]. In order to clarify this phenomenon, the current-voltage $(I-V)$ characteristics of the $(\mathrm{Zn}, \mathrm{Mg}) \mathrm{O}$ based MSM photodetectors both under dark conditions and illuminating above the optical bandgap energy were measured, as it shown in figure 5(b). In the dark, the current at $1 \mathrm{~V}$ decreases drastically with increasing $\mathrm{Mg}$ concentration, from $\sim 10^{-5}$ in $\mathrm{ZnO}$ to $\sim 10^{-10} \mathrm{~A}$ in $\mathrm{Zn}_{0.65} \mathrm{Mg}_{0.35} \mathrm{O}$, indicating that the films gradually become electrically compensated with increasing Mg content [34, 35]. This increase in the electrical compensation of the films with $\mathrm{Mg}$ content has a direct impact on the responsivity since the photogenerated carriers have to travel through a more resistive layer.

The large responsivities correspond to an apparent external quantum efficiency exceeding $100 \%$, which indicates an internal photoconductive gain potentially related to various phenomena. First, the Schottky barriers of the MSM photodiodes could be lowered as a result of photoexcited holes trapped at the metal/semiconductor interfaces. This effect was initially described and quantified by Katz et al in UV GaN Schottky photodiodes [36], and the concept has directly been applied to ZnO MSMs more recently [37]. Moreover, and since our films are polycrystalline, hole trapping at the grain boundaries, which also behave as potential barriers, could have a similar effect yielding a photoconductive gain. Finally, the photoionization of the acceptor-like deep levels typically present in high $\mathrm{Mg}$ content films can also increase the tunnel current through the Schottky barriers, as discussed in [5]. 


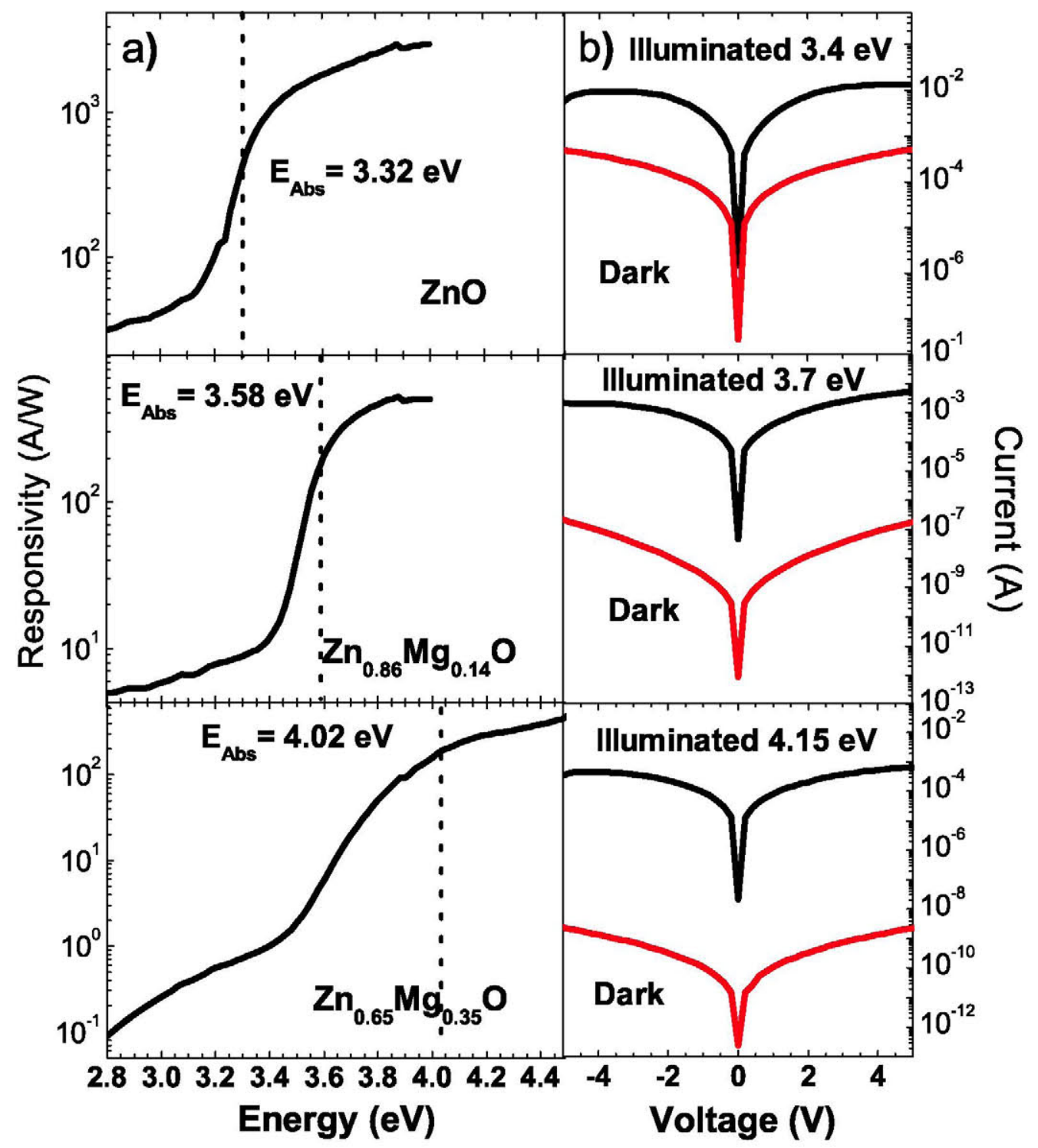

Figure 5. (a) Spectral response at $1 \mathrm{~V}$ and (b) IV curves under dark conditions and illumination above bandgap energy of the ( $\mathrm{Zn}, \mathrm{Mg}$ ) $\mathrm{O}$ MSM photodiodes with different $\mathrm{Mg}$ contents.

Note that a well-defined symmetrical rectifying behavior, typically of the back-to-back Schottky contacts in the MSM photodiodes, is observed for both dark and illuminated conditions. Furthermore, as shown in figure 6(b), the UV/dark contrast ratio of the $\mathrm{Zn}_{1-x} \mathrm{Mg}_{x} \mathrm{O}$-based photodetectors at $1 \mathrm{~V}$ bias tends to increase from 10 to $10^{7}$ with increasing $\mathrm{Mg}$ content. This contrast ratio is defined as the responsivity measured above optical bandgap divided by dark current, both measured at $1 \mathrm{~V}$. The maximum value is obtained for the $(\mathrm{Zn}, \mathrm{Mg}) \mathrm{O}$ films with $22 \%$ of $\mathrm{Mg}$. This value is comparable with that observed in the case of $\mathrm{Zn}_{0.82} \mathrm{Mg}_{0.18} \mathrm{O}$ grown by MOCVD [5]. However, the contrast ratio starts to drop drastically for $\mathrm{Mg}$ contents above $22 \%$, which might be due to the formation of defects associated with grain boundaries, and the beginning of phase separation. Indeed, the Stokes shift (figure 3), absorption edge broadening (figure 1(c)) and CL FWHM (figure 2(c)), discussed earlier in the text, all indicate a degradation of the optical properties of the films for the highest $\mathrm{Mg}$ contents.
In summary, we have studied $(\mathrm{Zn}, \mathrm{Mg}) \mathrm{O}$ films with different $\mathrm{Mg}$ contents ranging from 0 to $35 \%$ grown by SP. The absorption measurements show a well defined absorption edge, with a large blue shift from 3.30 to $4.11 \mathrm{eV}$, with increasing $\mathrm{Mg}$ content. To the best of our knowledge, this shift is the largest value reported in the literature using SP as the growth technique. With increasing $\mathrm{Mg}$ content an increase of both Stokes shift and CL/PL line width is observed, which were explained partially by the presence of statistical alloy disorder. In addition a large band tail of states is present in the higher $\mathrm{Mg}$ content films. This effect in combination with the larger sensitivity to potential fluctuations of the $(\mathrm{Zn}, \mathrm{Mg}) \mathrm{O}$ exciton, can account for the rest of the Stokes shift observed for larger $\mathrm{Mg}$ contents. Finally, $(\mathrm{Zn}, \mathrm{Mg}) \mathrm{O}$-based MSM photodiodes have been fabricated showing a blue shift from 3.32 to $4.02 \mathrm{eV}$, with high responsivity values $\left(10-10^{3} \mathrm{~A} / \mathrm{W}\right)$ and large UV/dark contrast ratios $\left(10-10^{7}\right)$, demonstrating the potential of SP for UV photodetection application. 


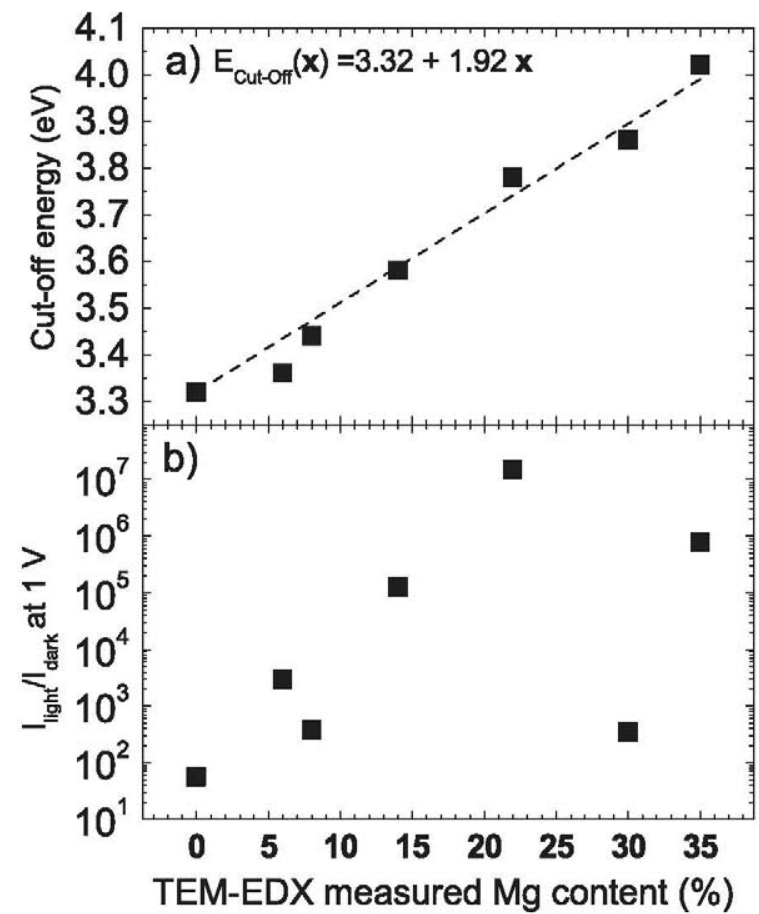

Figure 6. (a) Absorption edge energy and (b) $I_{\text {light }} / I_{\text {dark }}$ ratio at $1 \mathrm{~V}$ of the $(\mathrm{Zn}, \mathrm{Mg}) \mathrm{O}$ MSM photodetectors represented as a function of $\mathrm{Mg}$ content.

\section{Acknowledgments}

The authors would like to thank A Fraile for her contribution in the MSM processing and X Yinqiu for her contribution in the optical measurements. Support is acknowledged from the Ministry of Economy and Competitiveness (MINECO) through project TEC2011-28076-C02-01/02 and TEC2014$60173-\mathrm{C} 2-2$, the Generalitat Valenciana through projects Prometeo/2011-035 and ISIC/2012/008, and SCSIE University Valencia for providing the TEM-EDAX facilities. V Marin-Borras has been supported by the 'Atracció de Talent' fellowship from University of Valencia.

\section{References}

[1] Hou Y N, Mei Z X, Liu Z L, Zhang T C and Du X L 2011 Appl. Phys. Lett. 98103506

[2] Beek W J E 2004 Adv. Mater. 161009

[3] Parish G, Keller S, Kozodoy P, Ibbetson J P, Marchand H and Fini P T 1999 Appl. Phys. Lett. 75247

[4] Monroy E, Hamilton M, Walker D, Kung P, Sánchez F J and Razeghi M 1999 Appl. Phys. Lett. 741171

[5] Tabares G, Hierro A, Ulloa J M, Guzman A, Muñoz E, Nakamura A, Hayashi T and Temmyo J 2010 Appl. Phys. Lett. 96101112

[6] Yang W, Vispute R D, Choopun S, Sharma R P, Venkatesan T and Shen H 2001 Appl. Phys. Lett. 782787

[7] Liu K W, Shen D Z, Shan C X, Zhang J Y, Jiang D Y, Zhao Y M, Yao B and Zhao D X 2008 J. Phys. D. Appl. Phys. 41125104
[8] Pantelides S T, Mickish D J and Kunz A B 1974 Phys. Rev. B 105203

[9] Redondo-Cubero A, Hierro A, Chauveau J-M, Lorenz K, Tabares G, Franco N, Alvesa E and Muñoz E 2012 Cryst. Eng. Comm. 141637

[10] Park W I, Yi G-C and Jang H M 2001 Appl. Phys. Lett. 792022

[11] Koike K, Hama K, Nakashima I, Takada G, Ogata K, Sasa S, Inoue M and Yano M 2005 J. Cryst. Growth 278288

[12] Schmidt-Grund R, Schubert M, Rheinländer B, Fritsch D, Schmidt H, Kaidashev E M, Lorenz M, Herzinger C M and Grundmann M 2004 Thin Solid Films 455-456 500

[13] Minemoto T, Negami T, Nishiwaki S and Takakura H 2000 Thin Solid Films 372173

[14] Ji Z, Song Y, Xiang Y, Liu K, Wang C and Ye Z 2004 J. Cryst. Growth 265537

[15] Kamada Y, Kawaharamura T, Nishinaka H and Fujita S 2006 Japan. J. Appl. Phys. 45857

[16] Yoshino K, Oyama S and Yoneta M 2007 J. Mater. Sci. Mater. Electron. 19203

[17] Alaie Z, Mohammad Nejad S and Yousefi M H 2014 Mater. Sci. Semicond. Process. 2916

[18] Hou Y, Mei Z and Du X 2014 J. Phys. D. Appl. Phys. 47 283001

[19] Zhao J L, Sun X W, Tan S T, Lo G Q, Kwong D L and Cen Z H 2007 Appl. Phys. Lett. 91263501

[20] Bian J, Liu W, Liang H, Hu L, Sun J, Luo Y and Du G 2006 Chem. Phys. Lett. 430183

[21] Achary S R, Agouram S, Sánchez-Royo J F, Lopez-Ponce M, Ulloa J M, Muñoz E, Hierro A and Muñoz-Sanjosé V 2013 Cryst. Eng. Comm. 15182

[22] Srinivasan S, Bertram F, Bell A, Ponce F A, Tanaka S, Omiya H and Nakagawa Y 2002 Appl. Phys. Lett. 80550

[23] Suryanarayana Reddy A, Prathap P, Subbaiah Y P V, Ramakrishna Reddy K T and Yi J 2008 Thin Solid Films $\mathbf{5 1 6} 7084$

[24] Feng Z (ed) 2012 Handbook of Zinc Oxide and Related Materials: Volume Two, Devices and Nano-Engineering (Boca Raton, FL: CRC Press) p 562

[25] Yamamoto K, Tsuboi T, Ohashi T, Tawara T, Gotoh H, Nakamura A and Temmyo J 2010 J. Cryst. Growth 3121703

[26] Bergman L 2012 Handbook of Luminescent Semiconductor Materials (Boca Raton, FL : CRC Press) p 437

[27] Wassner T A, Laumer B, Maier S, Laufer A, Meyer B K, Stutzmann M and Eickhoff M 2009 J. Appl. Phys. 105 023505

[28] Tampo H, Shibata H, Maejima K, Yamada A, Matsubara K, Fons P, Niki S, Tainaka T, Chiba Y and Kanie H 2007 Appl. Phys. Lett. 91261907

[29] Roessler D M and Walker W C 1967 Phys. Rev. 157733

[30] Lin W H, Uwe W L, Holger T G, Liuwen C, Chou M C C and Wu J J 2013 Appl. Phys. Express 6061101

[31] Schubert E F, Göbel E O, Horikoshi Y, Ploog K and Queisser H J 1984 Phys. Rev. B 30813

[32] Zimmermann R 1990 J. Cryst. Growth 101346

[33] Heitsch S et al 2007 J. Appl. Phys. 101083521

[34] Hierro A, Tabares G, Ulloa J M, Muñoz E, Nakamura A, Hayashi T and Temmyo J 2009 Appl. Phys. Lett. 94232101

[35] Emre G, Tabares G, Arehart A, Chauveau J M, Hierro A and Ringel S A 2012 J. Appl. Phys. 112123709

[36] Katz O, Garber V, Meyler B, Bahir G and Salzman J 2001 Appl. Phys. Lett. 791417

[37] Liu J S, Shan C X, Li B H, Zhang Z Z, Yang C L, Shen D Z and Fan X W 2010 Appl. Phys. Lett. 973 